\title{
EFFECTS OF POLLEN AND RESOURCES ON SEED NUMBER AND OTHER FITNESS COMPONENTS IN AMELANCHIER ARBOREA (ROSACEAE: MALOIDEAE) ${ }^{1}$
}

\author{
DAVID L. GORCHOV ${ }^{2}$ \\ Department of Biology, University of Michigan, Ann Arbor, Michigan 48109
}

\begin{abstract}
A B S T R A C T
Most Amelanchier arborea flowers have 10 ovules, but the number of filled (embryo-containing) seeds per fruit is usually less than 10 and is highly variable within each individual plant. Because fruit developmental time correlates with seed number, this variation in seed number results in asynchronous fruit ripening. Field experiments tested whether seed number was pollen- or resource-limited. Manipulation of resources in the shoot at the time of fruit initiation by defoliation, girdling, fruit thinning, or foliar feeding had no significant effect on seed number per fruit, although fruit set and seed weight were affected. Supplemental crosspollination also had no demonstrable effect on seed number. Most ovules that do not become filled seeds are visible as small "undeveloped seeds"; these are not necessarily aborted seeds as this was also the fate of ovules in unpollinated carpels. Alternative hypotheses for the determination of seed number are proposed and discussed.
\end{abstract}

THE NUMBER OF SEEDS that mature per fruit is variable in many plant species and has several important ecological, evolutionary, and horticultural implications. Seed number has been studied as a component of yield (or fitness) for its importance to both the adjustment of reproductive output under varying environmental conditions (Wilbur, 1977; Primack, 1978; Wyatt, 1981; Schemske and Pautler, 1984; Stephenson, 1984; Garwood and Horvitz, 1985; Marshall, Levin, and Fowler, 1985, 1986; Galen and Weger, 1986) and the improvement of agricultural crop yield (Olsson, 1960; Adams, 1967; Harper, 1977). In addition to its direct contribution to total plant reproductive output, seed number per fruit often influences the proportion of flowers that develop into fruits (fruit set). For several plant species, fruits with

' Received for publication 22 June 1987; revision accepted 8 December 1987.

I am grateful to $\mathrm{K}$. Childs, J. Larsen, L. Whittingham, B. Crespi, and K. Olsson for helping with field work, W. Frasch and J. Palmer for use of equipment, and D. Bay for photography. C. Campbell examined ovules for signs of apomictic seed development. M. Cruzan, L. Nooden, J. Hancock, and E. Hanson advised me on experimental methods. J. Bronstein, G. Estabrook, B. Rathcke, D. Goldberg, B. Barnes, W. A. Robinson, and an anonymous reviewer provided useful comments on earlier drafts of this manuscript. R. Kushler, G. Estabrook, and R. Bush aided in data analysis. The Museum of Zoology, University of Michigan, provided access to the E. S. George Reserve and two ESGR scholarships. Additional support was provided by Rackham Block grants from the University of Michigan. This work represents part of a dissertation submitted in partial fulfillment of the requirements for a Ph.D. at the University of Michigan.

${ }^{2}$ Current address: Dept. of Biology, Princeton University, Princeton, NJ 08544. few developing seeds are more likely to abort than those with many seeds (see reviews by Stephenson, 1981; Stephenson and Bertin, 1983). By aborting fruits with low seed numbers, plants may improve the average quality of their offspring, either by eliminating fruits resulting from self-fertilization (Darwin, 1876, pp. 398-400) or in which there has been little pollen competition for ovules (Lee, 1984).

Seed number can affect seed dispersal in several ways. Seed number is correlated with mature fruit size in many wild (Willson and Schemske, 1980; Bookman, 1983; Garwood and Horvitz, 1985; Gorchov, 1985; Bronstein, $1986)$ as well as cultivated (Crane, 1964, p. 303; Wareing and Phillips, 1978, p. 123) species; dispersers sometimes discriminate among fruits on the basis of size (Wheelwright, 1985).

The ratio of pulp weight to seed weight usually decreases with increasing seed number (e.g., Willson and Schemske, 1980; Janzen, 1982). Because pulp is reward and seed is ballast to fruit-eating animals that disperse seeds, pulp : seed ratio should influence dispersers' preferences (Howe and Vande Kerckhove, 1980; Herrera, 1981 a, b). Similarly, seed number influences dispersal distance of some wind-dispersed species via its effects on mass/volume ratio (Casper and Wiens, 1981; Augspurger and Hogan, 1983; Augspurger, 1986).

Seed number may also affect the number of seedlings germinating in one place, and therefore sibling competition (Casper and Wiens, 1981). Predispersal seed predators may prefer fruits with more seeds (Herrera, 1984); where 
they don't have such a preference, spreading seeds few to a fruit reduces seed loss (Delph, 1986).

Seed number can also affect dispersal through its effects on ripening phenology. Within individual plants of some species, the number of seeds is strongly negatively correlated with the duration of fruit development and with ripening date (Aalders and Hall, 1961; Dempsey and Boynton, 1965; Brewer and Dobson, 1969; Varga and Bruinsma, 1976; Lee and Bazzaz, 1982; Gorchov, 1985). For these plants, variance in seed number results in ripening that is much more asynchronous than flowering (Gorchov, 1985). Thompson and Willson (1979) proposed that the asynchronous ripening of temperate, summer-fruiting, bird-dispersed plants is an adaptation to avoid satiation of seed dispersal agents.

In the course of testing Thompson and Willson's (1979) hypothesis, I became interested in the proximate (mechanistic) causes of asynchronous ripening. In the case of Amelanchier arborea, a summer-ripening small tree with bird-dispersed seeds, flower-fruit interval is highly negatively correlated with the number of filled seeds (Gorchov, 1985). Hence, a proximate explanation for asynchronous ripening in this species requires an understanding of why seed number varies among fruits. The importance of resources, pollination, and seed predation in the determination of seed number raises the larger question of which of these factors usually limits total plant reproductive output (Bierzychudek, 1981; Stephenson, 1981; Rathcke, 1983; Bawa and Webb, 1984). Snow (1986) showed that seed number is related to pollination intensity primarily in species with very many seeds per fruit. Other studies have demonstrated a relationship between seed number and resources (reviewed in Marshall et al., 1986).

One objective of this study was to determine whether manipulation of resources in a shoot at the time of fruit initiation affected fruit set, seed number, or seed weight in $A$. arborea. I also tested whether addition of xenogamous pollen to unbagged flowers increased fruit set or seed number compared to open-pollinated controls. In addition I attempted to determine whether "undeveloped seeds" were aborted or unfertilized ovules.

MATERIALS AND METHODS-Study site-Field work was done at the E. S. George Wildlife Reserve, Livingston County, Michigan, a research area maintained by the University of Michigan. Climate and vegetation for the Reserve have been described in Rogers (1942),
Cantrall (1943), and Cooper (1958). All Amelanchier arborea trees chosen for this study were from a dense population in oak-hickory forest within $15 \mathrm{~m}$ of a $270 \mathrm{~m}$ stretch of a dirt road that runs along the top of an esker (ridge).

Study species-Amelanchier arborea (Michx. f.) Fern. (Rosaceae: Maloideae), Downy Serviceberry, is a large shrub to small tree common in dry and mesic sites in eastern North America (Fernald, 1950; Barnes and Wagner, 1981). Species identifications were made using Voss (1985); voucher specimens were deposited at the University of Michigan Herbarium.

Amelanchier arborea is one of the first shrubs to bloom in the spring (late April-early May) at the study site; the white flowers open synchronously ( $90 \%$ of flowers on each plant open in two to five days, Gorchov, 1987) and are visited primarily by small bees (mostly Andrenidae and Halictidae) but also by other $\mathrm{Hy}$ menoptera, Diptera, and Coleoptera.

Flower morphology is similar to that described for A. laevis (Campbell et al., 1985) and A. alnifolia (Olson and Steeves, 1982): the gynoecium consists of five carpels each containing two ovules (hence a potential of 10 seeds per fruit), as in other Maloideae. The five styles appear fused but are distinct ("pseudo-syncarpous" cf. Carr and Carr, 1961) and diverge at the stigmas, enabling separate pollination of individual carpels (Fig. 1). The inflorescence is an elongate panicle and the terminal flower usually opens first. Inflorescences contain four to eleven flowers, with variability in flower number relatively low within individual plants $(\mathrm{SD}=0.7-2.2)$.

The fruits (pomes) are juicy, purple, and about $1 \mathrm{~cm}$ in diameter when fully ripe. The number of fully developed seeds per fruit ranges from one to 10 , and the balance of the 10 ovules develop into small or empty "seeds" that have seed coats but no embryo. Amelanchier arborea is the first species to ripen fleshy fruits each summer in southeastern Michigan; fruits ripen throughout June and early July. Fruit ripening is relatively asynchronous within trees; $90 \%$ of fruits ripen within 15-27 days (Gorchov, 1987). Fruits are eaten by a variety of birds and mammals; at the study site the principal seed disperser is the Cedar Waxwing, Bombycilla cedrorum. Chipmunks and other rodents are seed predators (Robinson, 1986), as are larvae of tortricid and geometrid moths.

Shoot-resource manipulations-Ten plants with many inflorescences accessible from the ground were chosen during flowering (18-26 


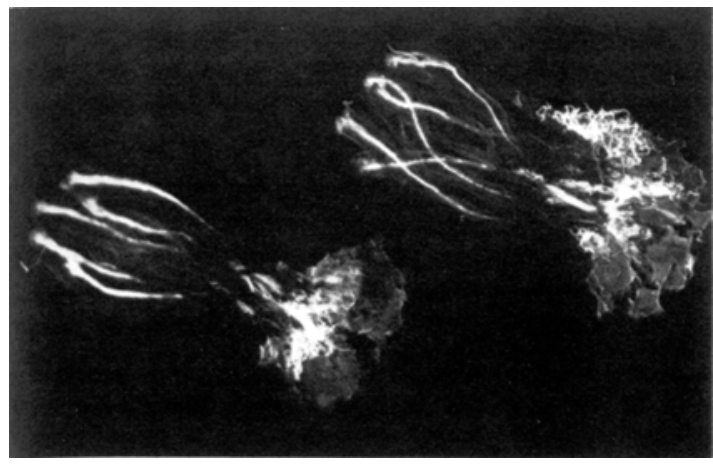

Fig. 1. Gynoecia from two Amelanchier arborea flowers stained with aniline blue and photographed under ultraviolet light (Martin, 1959). Fluorescing strands are pollen tubes. Each of the five styles of each flower has a distinct set of pollen tubes. Because ovaries were squashed, locules of the ovaries do not appear distinct.

April 1986). On each plant 10 shoots with inflorescences that were near the outside of the plant, were on different branches, and had the same number of flowers (or differed only by one flower) were chosen. On each plant, shoots were randomly assigned to the 10 treatments described in Table 1. Three of the treatments reduced the number of sinks competing with the target fruits for resources (Infr. Thin, Branch Thin, Infr. + Branch Thin). Two others were intended to increase the availability of mineral nutrients to the target fruits by foliar feeding (NPK, Trace). Four treatments were designed to decrease photosynthesis in, and/or translocation of photosynthate into, the shoot (Defoliation, Girdling, Defol. + Girdl., Defol. + 1/2 Girdl.).

Most treatments were done 28 April, the first day that styles had senesced on most flowers on all 10 plants. By this date, ovary swelling indicated that fruit initiation had occurred in most flowers. However, one shoot on each of 5 plants had no initiated fruits. These 5 shoots were not treated; instead the treatment they were designated to receive was applied to the shoot designated to receive treatment 10 . (Because of this, these five plants lacked a treatment 10 shoot.) Treatment 10 was done 29 April. Foliar feedings were done twice, 30 April and 12 May, days that were chosen because they were cloudy but rain was not forecast (minimizing the risks of fertilizer burn and wash-off, respectively).

Shoots were checked twice weekly until fruit ripening began 28 May; checks were then increased to every second day until all fruits had ripened or aborted (15 July). To minimize damage to developing seeds and fruits by moth larvae moving from fruit to fruit, small drops of Tanglefoot ${ }^{\circledR}$ were applied to larval entrance holes and pedicels of fruits that appeared to contain such larvae and branches were ringed with Tanglefoot ${ }^{\circledR}$ proximal to each shoot on 17 May. To prevent removal of fruits by birds and mammals, and to catch fruits that aborted or were knocked off, on 20 May mesh bags (made from green Orbit nylon net with $4 \mathrm{~mm}$ diameter openings) were placed around shoots containing one or more undamaged fruits. Fruits were collected when they were first observed nearly ripe (pink or red), when they were found loose in the mesh bag, or when it was clear that the tissue was dead.

Fresh weights of ripe fruits were obtained within two hours of collection using a Mettler P160 balance. Both ripe and aborted fruits were kept in individual glazed paper coin envelopes and refrigerated until dissected for seed counts (at most 15 days). Seeds were scored as filled (embryo present), empty (no embryo but longer than $2 \mathrm{~mm}$ ), eaten (by insect larvae), or undeveloped (shorter than $2 \mathrm{~mm}$ ). Presence of an

TABLE 1. Summary of shoot resource manipulation treatments. In each case, "shoot" refers to flowers, leaves, and stem that grew from a single bud that opened April 1986

\begin{tabular}{|c|c|}
\hline Treatment & Description \\
\hline 1. Control & No manipulation \\
\hline 2. Infr. Thin & $\begin{array}{l}\text { Most proximal developing fruit identified, all other developing fruits and past flowers } \\
\text { on infructescence cut off at end of pedicel }\end{array}$ \\
\hline 3. Branch Thin & $\begin{array}{l}\text { All developing fruits and past flowers on the four shoots closest to the target shoot } \\
\text { (as measured along branches) cut at end of pedicel }\end{array}$ \\
\hline 4. Infr. + Branch Thin & Fruits thinned on target shoot (as in 2) and on neighboring shoots (as in 3) \\
\hline 5. NPK & $\begin{array}{l}\text { Shoots sprayed twice with } 2,000 \text { ppm solution of Peters Professional Soluble Plant } \\
\text { Food }(20-20-20 \text { N-P-K) }\end{array}$ \\
\hline 6. Trace & Shoots sprayed twice with 2,500 ppm solution of Peters Soluble Trace Element Mix \\
\hline 7. Defoliation & All leaves on shoot cut off at base of blade \\
\hline 8. Girdling & $\begin{array}{l}\text { Bark scraped off on a } 2 \mathrm{~mm} \text { wide band of wood just proximal (within } 1 \mathrm{~cm} \text { ) of shoot } \\
\text { base }\end{array}$ \\
\hline 9. Defol. + Girdl. & Shoot defoliated and girdled as above \\
\hline 10. Defol. + $1 / 2$ Girdl. & Same as 9 except shoot girdled only halfway around stem \\
\hline
\end{tabular}


embryo could usually be determined by the plumpness of the seed; seeds of intermediate plumpness were cut open for inspection. Fresh weights of seeds of ripe fruits were obtained by drying seeds with a paper towel and then weighing on a Mettler HK60 balance. A dry weight was obtained for the pulp plus skin of each ripe fruit ("pulp dry weight") by carefully placing each in a paper coin envelope and drying at $40 \mathrm{C}$ for over one month, before reweighing on the Mettler HK60.

On one of the 10 plants no fruits matured on any of the treated or control shoots, so data analysis was limited to the other nine plants.

Pollination experiments - In order to determine whether augmentation of pollination results in increased seed number, two treatments were carried out: 1) open pollination (Open)flowers not manipulated, and 2) open plus cross pollination $(\mathrm{O}+\mathrm{C})$-flowers cross-pollinated by hand. To determine whether fruits ever set from apomixis or selfing, other inflorescences were bagged to exclude insects and their flowers not pollinated (Bagged). To determine whether unpollinated ovules become "undeveloped seeds" or are resorbed when they are in a fruit that matures, a fourth treatment was carried out in which inflorescences were bagged, two styles per flower were pinched off, and the other three cross-pollinated (B3C).

Five trees with a large number of inflorescences accessible from the ground were chosen for pollen manipulations. A few days before flowering began, the modal number of flower buds per inflorescence on each tree was estimated, and 20 widely spaced inflorescences that had the modal number $( \pm 1)$ of flower buds were selected. On each plant five inflorescences were randomly assigned to each of the four treatments.

Cross pollen for the $\mathrm{O}+\mathrm{C}$ and $\mathrm{B} 3 \mathrm{C}$ treatments was a mixture obtained from anthers of four other trees immediately prior to pollination. These trees (pollen donors) were located in the same general vicinity as the pollen receiving trees, but each pollen donor was at least $3.4 \mathrm{~m}$ from the nearest pollen recipient. Equal numbers of mature anthers from each pollen donor were placed in an Eppendorf centrifuge tube and mashed with a wooden toothpick. Pollen was applied to stigmas using a toothpick. Nearly all hand pollinations were done 22-25 April.

Inflorescences in the Bagged and $\mathrm{B} 3 \mathrm{C}$ treatments were bagged with white nylon cloth (Rosebar Glitter Organdy) with a mesh of about $0.2 \mathrm{~mm}$. These bags may not have excluded wind-borne pollen, but earlier findings that fruit set of bagged flowers is extremely low unless hand-crossed (Gorchov, 1985) indicated that through-the-bag cross pollination is infrequent at best. Inflorescences were bagged shortly before the first flowers opened: 17 April for one plant, 12 April for the other four plants. B3C inflorescences were checked daily during flower opening. On the first day a flower was open, two of its five styles were pinched off with a fine forceps and the remaining three cross pollinated. Bags were removed after the last flower had been hand pollinated, allowing insects to visit the flowers. Inflorescences in the Bagged treatment were kept bagged until all flowers showed signs of senescence (browning) on their styles (26-30 April).

In order to keep track of individual flowers and the fruits derived from each, inflorescences were checked daily from flower opening to 1 May, every second day 3-9 May, then twice weekly until fruit ripening began 28 May. Fruits were then checked every second day until all fruits had ether ripened or aborted (23 July). Moth larvae and fruits believed to contain larvae (entrance hole with frass extruding) were removed in mid-May, and Tanglefoot ${ }^{\circledR}$ was applied 17 May as described above for the shoot resource manipulations. Fruits were protected with mesh bags ( 25 May), collected when ripe or aborted (but not weighed), stored, dissected, and seeds counted (but not weighed) as described for the shoot resource manipulations.

Fruit set (number of fruits ripened $\div$ number of flowers sampled) was calculated for each plant for each treatment. Flowers that were killed by a hard frost on 22 April or collected for pollen-tube staining were not included in these calculations, nor were flowers whose styles senesced before I was able to cross-pollinate them in the $\mathrm{O}+\mathrm{C}(N=11)$ and B3C $(N=$ 29) treatments. Data from two plants were not included in further analyses. One plant lost most of its flowers in the 22 April frost, and another plant had very low fruit set for unknown reasons. Data for the other three plants were pooled for further analyses, as one-way analysis of variance (ANOVA) revealed no significant plant effects on seed number.

Data analysis -Comparison of fruit set among the shoot resource treatments, between each of these treatments and the Control, and between the Open and $\mathrm{O}+\mathrm{C}$ pollination treatments was done by $G$ test. To determine the effects of the resource manipulation treatments and individual plants on 1) filled seed number and 2) mean weight of filled seeds per fruit, two-way ANOVA was used, modelling treat- 
ment as a fixed effect and plant and planttreatment interaction as random effects. Classical ANOVA was not appropriate for this mixed model design because the data were unbalanced. Instead, maximum likelihood estimation of the ANOVA model parameters were calculated with the BMDP:3V program (Dixon, 1983). This program calculates likelihood ratio statistics for each null hypothesis (no treatment effect, no plant effect, and no interaction) which are tested for significance by $\chi^{2}$ test and not by the $F$ test of classical ANOVA. Only fruits without larval insect damage were used in these analyses. Fruits from the Defol. + Girdl. and Defol. + 1/2 Girdl. treatments were pooled because the treatments and the resultant seed numbers and weights were similar. In order to test the homogeneity of variances assumption of two-way ANOVA, the Box test was used to determine whether the variances in a) filled seed number, b) mean weight of filled seeds, and c) pulp dry weight were homogenous 1) across the nine plants and 2) across the 10 treatments. Variances of all three variables were homogenous across treatments, but only variance in seed weight was homogenous across plants. For seed number, the assumption of homogeneity of variances was satisfied by omitting the plant with the lowest variance. For pulp dry weight, this assumption was met by omitting a different plant, that with the highest variance in pulp dry weight. Therefore the two-way ANOVAs of seed number and pulp dry weight on plant and treatment were done only on fruits from eight plants. Seed number and pulp dry weight of Control fruit were compared to those of fruits in each of the other resource treatments (all nine plants pooled) by Student $t$ test. Comparison of seed weight between Control and other treatments was done by Mann-Whitney $U$ test, since variances were often unequal. Comparisons between Open and $\mathrm{O}+\mathrm{C}$ pollination treatments in seed number were done by $U$ test for the same reason. Means are expressed $\pm 1 \mathrm{SD}$.

RESULTS-Shoot resource manipulationsThe overall effect of shoot resource treatments on fruit set was highly significant ( $G=55.1$, df $=9, P<0.005$; Table 2). Fruit set was higher than the Control $(27 \%)$ for treatments that reduced the number of competing sinks, although this was significant only for the Infr. and Branch Thin treatment $(89 \%)$. Fruit set did not differ significantly from the Control in treatments where mineral nutrients were added by foliar feeding. There was no significant effect on fruit set from girdling or defoliation alone,
TABLE 2. Number of A. arborea flowers and ripe fruits, and fruit set (fruits ripened $\div$ flowers) in shoot resource manipulations. Treatments are described in Table 1. Fruit set in each treatment was compared to the control by $G$ test

\begin{tabular}{|c|c|c|c|c|}
\hline Treatment & $\begin{array}{l}\text { Flow- } \\
\text { ers }\end{array}$ & $\begin{array}{l}\text { Fruits } \\
\text { ripened }\end{array}$ & $\begin{array}{c}\% \\
\text { Fruit } \\
\text { set }\end{array}$ & $\begin{array}{c}\text { Signifi- } \\
\text { cance } \\
\text { com- } \\
\text { pared } \\
\text { to } \\
\text { control }\end{array}$ \\
\hline Control & 73 & 20 & 27 & \\
\hline Infr. + Branch Thin & 9 & 8 & 89 & $* * *$ \\
\hline Infr. Thin & 9 & 4 & 44 & ns \\
\hline Branch Thin & 72 & 29 & 40 & ns \\
\hline NPK & 71 & 21 & 30 & ns \\
\hline Trace & 75 & 17 & 23 & ns \\
\hline Defoliation & 66 & 18 & 27 & ns \\
\hline Girdling & 70 & 16 & 23 & ns \\
\hline Defol. + 1/2 Girdl. & 46 & 5 & 11 & * \\
\hline Defol. + Girdl. & 69 & 3 & 4 & $* * *$ \\
\hline
\end{tabular}

$$
\begin{array}{rl}
\text { ns } P & >0.05 \\
* & P<0.05 \\
* * * & P<0.001
\end{array}
$$

but fruit set was significantly lower than the Control on shoots that were both defoliated and girdled (4\%) or defoliated and half-girdled (11\%).

The total number of seeds (including eaten, empty, and undeveloped seeds) per fruit ranged from eight to 11 , but equalled 10 for $92 \%$ of fruits.

Filled seed number per fruit did not differ among the treatments (Table 3 ). The two-way ANOVA of seed number on plant and treatment showed a significant plant effect $\left(\chi^{2}=\right.$ 4.0 , $\mathrm{df}=1, P<0.05$ ) but no significant treatment or interaction effects. Seed number in each of the treatments was not significantly different from the Control.

Fruits that aborted had fewer filled seeds than fruits that ripened. Fruits that aborted 2431 May had a mean of $0.5 \pm 1.5$ filled seeds and those that aborted during June had $1.8 \pm$ 2.4 filled seeds, compared to $6.7 \pm 2.6$ filled seeds for fruits that ripened (all treatments pooled).

Mean filled seed weight per fruit did differ among the shoot resource treatments (Table 3 ). The two-way ANOVA revealed a significant treatment effect $\left(\chi^{2}=36.7, \mathrm{df}=8, P<0.001\right)$ as well as significant plant $\left(\chi^{2}=27.1, \mathrm{df}=1\right.$, $P<0.001)$ and interaction $\left(\chi^{2}=4.6, \mathrm{df}=1\right.$, $P<0.05)$ effects. Seeds were heaviest in the Infr. + Branch Thin and Infr. Thin treatments. Sample size in each of these two treatments was too small for Mann-Whitney $U$ test, but when pooled, these seed weights were significantly heavier than those of Control fruits ( $U$ $\left.=29, N_{1}=10, N_{2}=18, P<0.01\right)$. There was 
TABLE 3. Filled seed number and mean filled seed weight per undamaged A. arborea fruit in shoot resource manipulations

\begin{tabular}{lcccc}
\hline \multicolumn{1}{c}{ Treatment } & $\begin{array}{c}\text { Undamaged } \\
\text { ripe fruits }\end{array}$ & Filled seeds per fruit & $\begin{array}{c}\text { Mean filled seed weight } \\
\text { per fruit (m) }\end{array}$ & Pulp dry weight (mg) \\
\hline Control & 18 & $7.4(2.3)^{\mathrm{a}}$ & $4.8(0.8)$ & $37.9(12.0)$ \\
Infr. + Branch Thin & 6 & $6.2(3.0)$ & $7.0(1.0)$ & $41.0(14.8)$ \\
Infr. Thin & 4 & $9.0(0.8)$ & $5.9(1.4)$ & $39.0(10.7)$ \\
Branch Thin & 25 & $6.6(2.3)$ & $5.0(1.4)$ & $36.4(13.8)$ \\
NPK & 16 & $5.8(2.6)$ & $4.9(1.5)$ & $35.9(13.0)$ \\
Trace & 16 & $6.2(2.9)$ & $5.4(1.4)$ & $41.5(14.4)$ \\
Defoliation & 12 & $7.0(2.1)$ & $4.1(1.0)$ & $38.3(14.0)$ \\
Girdling & 14 & $6.0(3.2)$ & $5.5(1.3)$ & $43.2(13.4)$ \\
Defol. + 1/2 Girdl. & 5 & $8.2(2.5)$ & $4.8(0.8)$ & $34.0(4.4)$ \\
Defol. + Girdl. & 3 & $6.7(3.5)$ & $4.7(0.8)$ & $39.9(18.9)$ \\
\hline
\end{tabular}

"Mean (SD).

a marginally significant tendency for seeds to be lighter in the Defoliation treatment than in the Control $\left(U=63, N_{1}=12, N_{2}=18, P=\right.$ $0.06)$. The other treatments that interfered with photosynthesis and/or translocation had no effect. Nutrient addition also did not affect seed weight.

Plants that averaged more filled seeds per fruit tended to have lighter mean filled seed weights $(r=-0.65, N=9, P=0.06)$. Similarly, within individual plants, fruits with more seeds tended to have lighter seeds: the correlation between filled seed number and mean weight was negative for eight of the nine plants, although significantly so for only two. Overall, mean weight of filled seeds declined slightly with increasing filled seed number (slope $=$ $-0.22 \mathrm{mg} \cdot$ seed $^{-2}, N=119, F=24, P<0.001$, $r^{2}=0.17$ ).

There was a significant plant effect on pulp dry weight $\left(\chi^{2}=15.1, \mathrm{df}=1, P<0.001\right)$ but there was no significant treatment effect or interaction. There were no significant differences in pulp dry weight between Control fruits and any treatment (Table 3). Among the nine plants mean pulp dry weight was not correlated with mean filled seed weight $(r=0.44, P>0.2)$ or number $(r=0.15)$. Among all fruits, pulp dry weight increased with filled seed number (slope $=1.8 \mathrm{mg} / \mathrm{seed}, N=119, F=17.3, P<0.001$, $r^{2}=0.13$ ). However, on a per filled seed basis, pulp dry weight declined (slope $=-1.3 \mathrm{mg}$. seed $^{-2}, N=119, F=89, P<0.001, r^{2}=0.43$ ), indicating a decrease in pulp:seed ratio with increasing seed number.

Pollination experiments - The total number of seeds (âl categories) ranged from nine to 11 $(91 \%$ with 10$)$ in the Open treatment and from eight to $10(96 \%$ with 10$)$ in the $\mathrm{O}+\mathrm{C}$ treatment.

Fruit set was higher, but not significantly so, in the Open + Cross $(0+C)$ treatment compared to Open pollinated flowers (Table 4).

The number of filled seeds per fruit did not differ between the two treatments but was more variable in the $\mathrm{O}+\mathrm{C}$ treatment. The number of empty seeds was greater and more variable in the Open treatment. The number of undeveloped seeds was not different between treatments, but was more variable in the $\mathrm{O}+\mathrm{C}$ treatment.

Fruit set was zero in the Bagged treatment, confirming earlier findings of no (or very low) self-compatibility or apomixis (Robinson, 1982; Gorchov, 1985). Other evidence that $A$. arborea is not apomictic is the low frequency of multiple megagametophytes in the ovules (Campbell, Greene, and Bergquist, 1987; C. Campbell, unpublished data).

Fruit set was low in the $\mathrm{B} 3 \mathrm{C}$ treatment. These fruits had one to six filled seeds and most of the balance of the 10 ovules in each fruit were accounted for by undeveloped seeds. As would be expected if these undeveloped seeds represent unfertilized ovules, all but one of these fruits contained two adjacent carpels containing two undeveloped seeds each.

Discussion-Shoot resources-Shoot resource levels were affected by at least some of the manipulations, as evidenced by the changes in fruit set and seed weight. Reducing the number of competing sinks by thinning fruits tended to increase fruit set and seed weight. These effects were greatest in the Infr. and Branch Thin treatment, where there was only one initiated fruit per five infructescences. Thinning an entire small $A$. arborea shrub to one initiated fruit per infructescence also resulted in high mean weight of filled seeds $(7.0 \pm 1.3 \mathrm{mg}, N$ $=9$ fruits, Gorchov, 1987). Treatments that both reduced local photosynthesis (by defoliation) and interfered with transport of re- 
TABLE 4. Fruit set and seed numbers for four pollination treatments on three A. arborea plants

\begin{tabular}{|c|c|c|c|c|c|c|}
\hline \multirow[b]{2}{*}{ Treatment } & \multirow[b]{2}{*}{ Flowers } & \multirow[b]{2}{*}{ Fruits ripened ${ }^{a}$} & \multirow[b]{2}{*}{$\%$ Fruit set } & \multicolumn{3}{|c|}{ Seeds per fruit: mean (SD) } \\
\hline & & & & Filled & Empty & Undeveloped \\
\hline Open & 118 & $45(41)$ & $\begin{array}{l}38 \\
\text { ns }^{b}\end{array}$ & $\begin{array}{l}7.5(1.8) \\
\text { ns ** }\end{array}$ & $\begin{array}{l}1.1(1.3) \\
* * * *\end{array}$ & $\begin{array}{l}1.4(1.5) \\
\text { ns **** }\end{array}$ \\
\hline $\mathrm{O}+\mathrm{C}^{\mathrm{c}}$ & 101 & $48(41)$ & 46 & $7.2(2.6)$ & $0.5(0.8)$ & $2.1(2.5)$ \\
\hline B3 $C^{\mathrm{d}}$ & 93 & $9\left(6^{\mathrm{e}}\right)$ & 10 & $3.4(2.1)$ & $1.0(1.0)$ & $5.6(2.5)$ \\
\hline Bagged & 117 & 0 & & & & \\
\hline
\end{tabular}

a Total (undamaged). Only undamaged fruits were included in the analysis of seeds per fruit.

- Statistical significance of differences between Open and $\mathrm{O}+\mathrm{C}$ treatments are given in this row. Fruit set was compared by $G$ test, seed number by Mann-Whitney $U$ test, and variance in seed number by $F$ test.

$* P<0.05,{ }^{* *} P<0.01,{ }^{* * *} P<0.005$, ns $P>0.05$.

c Open + Cross-pollinated.

d Bagged + three styles cross-pollinated; two styles pinched off.

e One fruit not inspected so sample size equals 5 for seed numbers.

sources to the shoot (half or complete girdling) dramatically reduced fruit set. However, defoliation alone had no significant effect on fruit set and only marginally reduced seed weight, and girdling alone did not affect either.

Despite the effects of some of these treatments on fruit set and/or seed weight, none resulted in fruits with filled seed numbers differing significantly from the control. These results suggest that $A$. arborea does not adjust seed number to local resource levels. Alternatively, resources may influence the number of seeds that begin to develop, but due to the preferential abortion of few-seeded fruits this effect is manifested in differences in fruit set. In this scenario mean seed number per ripened fruit should still reflect shoot resources, but differences among treatments would be lessened by differential abortion. Thus this hypothesis predicts a correlation between fruit set and seed number among the treatments, a prediction not supported by these data $(r=$ $-0.12, N=10$ ). Another prediction is that differences in seed number among treatments would be more apparent when aborted fruits were included in the analysis. When fruits aborting after 20 May (when mesh bags were put in place) were included, the finding that treatments did not differ in seed number was not qualitatively changed (one-way ANOVA $F=1.2$, df $=8,120, P>0.5$ ). Most fruit abortions occurred before 20 May but seed numbers were not obtained for these. Thus, while there is no direct support for the hypothesis that resource effects on fruit set are mediated by seed number, criticial data are lacking. Even if preabortion seed number is determined by resources, but seed-number-dependent fruit abortion somehow compensates for it, seed number in mature fruits would still end up independent of resources.

Further evidence that seed number is not dependent on resources comes from small $A$. arborea plants thinned throughout to one initiated fruit per infructescence. On one plant filled seed numbers were low $(4.9 \pm 2.5, N=$ $30)$ but on another they were high $(8.1 \pm 1.6$, $N=19$, Gorchov, 1987). This difference is consistent with the significant differences among plants in filled seed number detected by the two-way ANOVA. Plants that averaged more seeds per fruit tended to have lighter seeds, suggesting intrinsic differences among plants in basic allocation patterns.

The results of the shoot resource manipulations suggest that photosynthate, rather than any mineral nutrient, was limiting to fruit number and seed weight. Neither macronutrients (NPK) nor trace element fertilization had a demonstrable effect on any of the measured components of fitness, whereas reducing the number of physiological sinks competing for resources, by fruit-thinning, increased fruit number and/or seed weight. Either girdling or defoliation alone had no effect on fruit set. However, the combination of defoliation and partial or complete girdling drastically reduced fruit set. This supports the conclusion that photosynthate was the limiting resource: due to defoliation, fruits on these shoots did not have local sources of photosynthate (except from storage in the small segment of wood distal to the girdle) and as a result of girdling they were partially or completely cut off from photosynthate translocated from the rest of the plant. These fruits could still be supplied with mineral nutrients through xylem, although defoliation could reduce this supply by slowing transpiration.

An alternative explanation of the lack of response to foliar feeding of mineral nutrients is that these minerals were not absorbed by the leaf tissue. This is unlikely, since foliar absorption of minerals is generally good in another 
member of the Maloideae, the apple, and is better in young leaves than old (Swietlik and Faust, 1984). Another caveat is the possibility that the other manipulations affected fruit set and seed weight through changes in endogenous hormone levels, rather than resources.

Although each of the classes of resource manipulation described here has been shown to affect seed number in other species, seed number is less frequently affected by resource levels than are other fitness components such as fruit set and seed weight. (See Marshall et al., 1986, for a review.) Most of the studied to date have been done on herbaceous plants, particularly crops and wild annuals. Woody plants have been less often considered in these studies. The data available for woody species generally show an effect of resource manipulation on fruit number (Jaumien, 1968; Aalders, Hall, and Forsyth, 1969; Stephenson, 1980; Wyatt, 1981; Bertin, 1982; Swietlik and Faust, 1984; Dennis, 1986). Changes in seed number or weight have been reported less frequently, but both declined following defoliation in two tree species (Janzen, 1976; Stephenson, 1980) and seed number was increased by flower thinning in apple (Weinbaum and Simons, 1976).

Pollination-The absence of a significant difference in filled seed number between openpollinated flowers and those receiving supplemental cross pollination indicates that filled seed number is not pollen limited in $A$. arborea. In her review, Snow (1986) reported that seed number is not determined by quantity of compatible pollen deposited on the stigma in most species, but this result varied with average seed number. Only one of 14 species averaging 215 seeds per fruit has been shown to have seed number pollen limited, compared to five of 11 species with 21-500 seeds (Snow, 1986, table 4). Presumably, for those species with a small to moderate number of ovules, if compatible pollen reaches a flower there is usually enough to fertilize a sufficient number of ovules to cause a fruit to develop; the number of seeds in the fruit may vary but is not correlated with the amount of pollen applied. Amelanchier arborea falls into this category, as it has only 10 ovules per flower.

"Undeveloped seeds"-Most ovules that did not mature into filled seeds became small "undeveloped seeds." It is crucial to determine whether the latter represent unfertilized ovules or ovules that were fertilized but later aborted. If the former, then seed number is primarily determined by fertilization; if the latter, then it is determined mostly by seed abortion, which may be mediated by resources.

In order to determine whether unfertilized ovules became undeveloped seeds, I examined mature fruit in which some of the ovules were known to be unfertilized. These fruits were obtained by taking advantage of $A$. arborea's five-carpellate morphology (Fig. 1). The two ovules in each carpel can only be fertilized by pollen germinating on that carpel's stigma. Pinching off two adjacent styles and cross-pollinating the other three on flowers from which pollinators were excluded (treatment B3C), resulted in fruits that could mature but would contain at least four unfertilized ovules. These fruits each had a total seed count (filled + empty + undeveloped) of 10 (as did nearly all fruits in the other treatments) indicating that unfertilized ovules are not resorbed. Further evidence that the ovules in the unpollinated carpels become "undeveloped seeds" is the finding that most of these fruits had two adjacent carpels with two undeveloped seeds each. Therefore, the undeveloped seeds found in unmanipulated fruits may also derive from unfertilized ovules, although some may result from ovules that are fertilized but later abort.

Alternative hypotheses-Neither quantity of compatible pollen nor resources in the shoot during fruit initiation appear to influence the number of filled seeds per fruit in A. arborea, yet the number of filled seeds in unmanipulated fruits varies from 1 to 10 , and is variable within each plant. I propose several alternative hypotheses and evaluate each in light of the available data.

Seed predation: Although many fruits parasitized by lepidopteran larvae failed to ripen, some ripened but had some of their seeds eaten. This seed predation may explain some of the variation in filled seed number, but most ripening fruits were undamaged and filled seed number was highly variable among them. Including parasitized fruits in the analyses did not qualitatively change the findings that neither shoot resources nor pollination treatments significantly affected seed number. Fungi may be responsible for the death of some or all of the empty seeds, but the latter were uncommon compared to undeveloped seeds. Seed predation or fungal infection could explain the remaining variability only if these undeveloped seeds were the result of attack early in seed development.

Pollen blockage: Self-pollen deposited by insects or autogamously might cover enough of 
the surface of a stigma to prevent the germination of compatible pollen arriving subsequently. Similarly, the upper part of a style might clog with the pollen tubes from selfpollen (incompatibility in the Maloideae is gametophytic [de Nettancourt, 1977] which is associated with stylar inhibition). Growth of pollen tubes through a style may be blocked by improperly developed stylar transmitting tissue or wounds in the style. In any of these situations, seed number would be limited by fertilization, but supplemental cross pollination would have no effect, as reported here.

Ovule infertility: Some ovules may not develop into seeds because they are incapable of being fertilized. One proximate cause of ovule infertility is ovule degeneration, which refers to the cessation of development of an ovule before fertilization, as has been reported in Quercus (Mogensen, 1975), soybean (Abernethy et al., 1977), and pear (Jaumien, 1968).

An alternative proximate cause of ovule infertility is ovule senescence. In apple (Dennis, 1986), pear (Herrero, 1983), and sweet cherry (Stosser and Anvari, 1983) ovules mature a few days after anthesis but begin to senesce several days later if not fertilized. Ovule senescence appears to be the reason fruit set (and for pear, seeds per fruit) declines with increasing time between anthesis and hand-pollination in these species. However, seeds per fruit was not correlated with number of days between anthesis and fruit initiation in an intensively studied $A$. arborea tree (Gorchov, 1987).

Early abortion of fertilized ovules: Guth and Weller (1986) found that a large proportion of Oxalis magnifica ovules aborted during the first few days after fertilization. A fertilized ovule might fail to develop due to 1) genetic incompatibility between the male and female genomes manifested postzygotically, or 2) maternal resources limitation.

The shoot resource manipulations reported here had no effect on seed development, but they were done at or shortly after the time of fruit initiation. It is possible that resource levels at some stage before fruit initiation do influence whether a fertilized ovule develops into a filled seed. This hypothesis is supported by the fact that fruits from terminal flowers, which may have better vascular connections, average significantly more filled seeds than those from lateral flowers (Gorchov, 1987). However, among the lateral fruits, there was no trend of seed number with flower position. An alternative explanation for lower seed number in lateral fruit, advanced for apples (Weinbaum and Simons, 1976), is premature ovule degen- eration due to inhibition from the terminal flower.

Although earlier initiating fruits might be expected to have a resource advantage over later fruits, there was no correlation between seed number and fruit initiation date (Gorchov, 1987).

Carpel not adequately vascularized: Some ovules may abort due to resource shortage, but the shortage may be due to inadequate vascular connections, rather than the nutritional status of the shoot or developing fruit.

Testing the alternatives - It is possible to distinguish among the above alternative hypotheses by examining the spatial pattern of filled seeds. Certain of the hypotheses (pollen blockage, carpel vascularization) predict that the two ovules in a carpel should either both fail or both develop into seeds. Others (ovule degeneration, postzygotic incompatibility) predict that the fate of an ovule should be independent of that of its neighbor. An examination of the distribution of ovules within carpels in a set of open pollinated fruit, and comparison to that generated by a simulation, revealed that ovule failure is partially, but not completely, dependent on carpel membership (Gorchov and Estabrook, 1987). Thus neither a hypothesis that predicts both ovules should develop or fail together, nor one that predicts that ovule fate is independent of its neighbor, can be the sole determinant of seed number in $A$. arborea, although either may be among the causes.

Ecological consequences and evolutionary significance-Aborted $A$. arborea fruits have fewer filled seeds than matured fruits, suggesting selective abortion of few-seeded fruits, as has been reported in several other species (Stephenson, 1981; Stephenson and Bertin, 1983). Whether this results in higher average offspring quality (Darwin, 1876, pp. 398-400; Lee, 1984) was not determined. Multiseeded fruits are more "efficient" for the parent plant, as the mass of pulp and skin per seed declined with increasing seed number. This decrease in pulp to seed ratio would make many-seeded fruits less profitable to frugivores (Howe and Vande Kerckhove, 1980; Herrera, 1981a, b), but it is not known whether frugivores discriminate among Amelanchier fruits based on their seediness. Fruits ripening early in the season, before fruits of other species become available, tend to be eaten more promptly. Since ripening in $A$. arborea occurs earlier for fruits with more filled seeds (Gorchov, 1985), dispersal may be more successful for seeds in 
many-seeded fruits, although subsequent seedling competition may be greater.

Filled seed number is variable within each $A$. arborea individual and this variability persists despite changes in available resources. As a consequence, great variability exists in the flower-fruit interval and ripening date of the fruits on individual plants (Gorchov, 1985). Such asynchronous ripening in a summerfruiting, animal-dispersed plant has been proposed to be an adaptation to avoid satiation of resident seed-dispersal agents (Thompson and Willson, 1979), although field manipulations of fruit displays do not support this hypothesis (Gorchov, 1988). Although it is difficult to evaluate an evolutionary hypothesis such as this, it is made much less plausible if the purported adaptation can be shown to be a simple consequence of central features of the organism's biology. Asynchronous ripening in A. arborea appears to be a consequence of variability in seed number. If seed number were determined simply by pollination success, resource availability, or seed predation, it would be difficult to argue that variation in seed number is an adaptation to promote asynchronous ripening. However, the results presented here indicate that seed number remains variable despite manipulations of pollen and resources. Hence, we should continue to consider the possibility that this variation in seed number is maintained by the parent plant and that the resultant asynchronous ripening is an adaptation.

\section{LITERATURE CITED}

Aalders, L. E., and I. V. Hall. 1961. Pollen incompatibility and fruit set in lowbush blueberries. Canad. J. Gen. Cytol. 3: 300-307.

,-- AND F. R. FORSYTH. 1969. Effects of partial defoliation and light intensity on fruit set and berry development in the lowbush blueberry. Hort. Res. 9: 124-129.

Abernethy, R. H., R. G. Palmer, R. Shibles, and I. C. ANDERSON. 1977. Histological observations on abscising and retained soybean flowers. Canad. J. Plant Sci. 57: 713-716.

AdAMS, M. W. 1967. Basis of yield component compensation in crop plants with special reference to the field bean, Phaseolus vulgans. Crop Sci. 7: 505-510.

Augspurger, C. K. 1986. Double- and single-seeded indehiscent legumes of Platypodium elegans: consequences for wind dispersal and seedling growth and survival. Biotropica 18: 45-50.

$\longrightarrow$, AND K. P. HoGAN. 1983. Wind dispersal of fruits with variable seed number in a tropical tree (Lonchocarpus pentaphyllus): Leguminosae. Amer. J. Bot. 70: 1031-1037.

BARNes, B. V., AND W. H. WAGNER, JR, 1981. Michigan trees. University of Michigan Press, Ann Arbor, MI.

BAWA, K. S., AND C. J. WeBB. 1984. Flower, fruit, and seed abortion in tropical forest trees: implications for the evolution of paternal and maternal reproductive patterns. Amer. J. Bot. 71: 736-751.

BERTIN, R. I. 1982. The ecology of sex expression in red buckeye. Ecology 63: $445-456$.

BierzyCHUdek, P. 1981. Pollinator limitation of plant reproductive effort. Amer. Naturalist 117: 838-840.

BoOKMAN, S. S. 1983. Costs and benefits of flower abscission and fruit abortion in Asclepias speciosa. Ecology 64: 264-273.

Brewer, J. W., AND R. C. Dobson. 1969. Seed count and berry size in relation to pollinator level and harvest date for the highbush blueberry, Vaccinium corymbosum. J. Econ. Entomol. 62: 1353-1356.

BronsteIN, J. L. 1986. Coevolution and constraints in a Neotropical fig-pollinator wasp mutualism. Ph.D. dissertation. University of Michigan, Ann Arbor, MI.

Campbell, C. S., C. W. Greene, B. F. Neubauer, and J. M. Higgins. 1985. Apomixis in Amelanchier laevis, Shadbush (Rosaceae, Maloideae). Amer. J. Bot. 72: 1397-1403.

$\longrightarrow,-$, AND S. E. Bergquist. 1987. Apomixis and sexuality in three species of Amelanchier, shadbush (Rosaceae, Maloideae). Amer. J. Bot. 74: 321 328.

Cantrall, I. J. 1943. The ecology of the Orthoptera and Dermaptera of the George Reserve, Michigan. Misc. Publ. Mus. Zool. Mich. 54: 1-182.

Carr, S. G. M., AND D. J. CARr. 1961. The functional significance of syncarpy. Phytomorphology 11:240 256.

CASPER, B. B., AND D. Wiens. 1981. Fixed rates of random ovule abortion in Cryptantha flava (Boraginaceae) and its possible relation to seed dispersal. Ecology 62: 866-869.

COOPER, A. W. 1958. Plant life forms as indicators of microclimate. Ph.D. dissertation, University of Michigan, Ann Arbor, MI.

Crane, J. C. 1964. Growth substances in fruit setting and development. Annual Rev. Pl. Physiol. 15: 303326.

DARWIN, C. 1876. The effects of cross and self fertilization in the vegetable kingdom. John Murray, London.

DE Nettancourt, D. 1977. Incompatibility in angiosperms. Springer-Verlag, Berlin.

DELPH, L. F. 1986. Factors regulating fruit and seed production in the desert annual Lesquerella gordonii. Oecologia 69: 471-476.

Dempsey, W. H., AND J. E. Boynton. 1965. Effect of seed number on tomato fruit size and maturity. Proc. Amer. Soc. Hort. Sci. 86: 575-581.

Dennis, F. G., JR. 1986. Apple. In S. P. Monselise [ed.], CRC handbook of fruit set and development. CRC Press, Boca Raton, FL.

Dixon, W. J. [ED.] 1983. BMDP statistical software. University of California Press, Berkeley, CA.

Fernald, M. L. 1950. Gray's manual of botany. 8th ed. American Book, New York.

Galen, C., AND H. G. Weger. 1986. Re-evaluating the significance of correlations between seed number and size: evidence from a natural population of the lily, Clintonia borealis. Amer. J. Bot. 73: 346-352.

Garwood, N. C., AND C. V. Horvitz. 1985. Factors limiting fruit and seed production of a temperate shrub, Staphylea trifolia L. (Staphylaceae). Amer. J. Bot. 72: 453-466.

Gorchov, D. L. 1985. Fruit ripening asynchrony is related to variable seed number in Amelanchier and Vaccinium. Amer. J. Bot. 72: 1939-1943.

- 1987. Proximate and ultimate causes of fruit 
ripening asynchrony in vertebrate-dispersed woody plants in southeastern Michigan. Ph.D. dissertation, University of Michigan, Ann Arbor, MI.

__. In press. Does asynchronous fruit ripening avoid satiation of seed dispersers? A field test. Ecology.

$\longrightarrow$, AND G. F. ESTABROOK. 1987. A test of several hypotheses for the determination of seed number in Amelanchier arborea, using simulated probability distributions to evaluate data. Amer. J. Bot. 74: 18931897.

Guth, C. J., AND S. G. Weller. 1986. Pollination, fertilization, and ovule abortion in Oxalis magnifica. Amer. J. Bot. 73: 246-253.

HARPER J. L. 1977. Population biology of plants. Academic Press, London.

HerRera, C. M. 1981 a. Are tropical fruits more rewarding to dispersers than temperate ones? Amer. Naturalist 118: 896-907

_- $1981 \mathrm{~b}$. Fruit variation and competition for dispersers in natural populations of Smilax aspera. Oikos 36: $51-58$.

- 1984. Selective pressures on fruit seediness: differential predation of fly larvae on the fruits of Berberis hispanica. Oikos 42: 166-170.

Herrero, M. 1983. Factors affecting fruit set in "Agua de Aranjuez" pear. Acta Hort. 139: 91-96.

Howe, H. F., AND G. A. VANDE Kerckhove. 1980. Nutmeg dispersal by tropical birds. Science 2 10: 925-927.

JANZEN, D. H. 1976. Effect of defoliation on fruit-bearing branches of the Kentucky Coffee Tree, Gymnocladus dioicus (Leguminosae). Amer. Midl. Naturalist 95: 474-478.

-1982. Variation in average seed size and fruit seediness in a fruit crop of a Guanacaste tree (Leguminosae: Enterolobium cyclocarpum). Amer. J. Bot. 69: 1169-1178.

JAumien, F. 1968. The causes of poor bearing of pear trees of the variety "Doyenne de Comice." Acta Agrobot. 21: 75-106.

LEE, T. D. 1984. Patterns of fruit maturation: a gametophyte competition hypothesis. Amer. Naturalist 123: 427-432.

—, AND F. A. BAzZAZ. 1982. Regulation of fruit maturation pattern in an annual legume, Cassia fasciculata. Ecology 63: 1374-1388.

Marshall, D. L., D. A. Levin, AND N. C. Fowler. 1985. Plasticity in yield components in response to fruit predation and date of fruit initiation in three species of Sesbania (Leguminosae). J. Ecol. 73: 71-81.

,-- AND $\longrightarrow$ 1986. Plasticity of yield components in response to stress in Sesbania macrocarpa and Sesbania vesicaria (Leguminosae). Amer. Naturalist 127: 508-521.

Martin, F. W. 1959. Staining and observing pollen tubes in the style by means of fluorescence. Stain Tech. 34: 125-128.

Mogensen, H. L. 1975. Ovule abortion in Quercus (Fagaceae). Amer. J. Bot. 62: 160-165.

Olson, A. R., AND T. A. STEEves. 1982. Structural changes in the developing fruit wall of Amelanchier alnifolia. Canad. J. Bot. 60: 1880-1887.

Olsson, G. 1960. Some relations between number of seeds per pod, seed size, and oil content, and the effects of selection for these characters in Brassica and Sinapis. Hereditas 46: 29-70.
Primack, R. B. 1978. Regulation of seed yield in Plantago. J. Ecology 66: 835-847.

RATHCKE, B. 1983. Competition and facilitation for pollination. In L. Real [ed.], Pollination biology, 305329. Academic Press, New York.

Robinson, W. A. 1982. Experimental taxonomy in the genus Amelanchier II: do the taxa in the genus $A m e$ lanchier form an agamic complex? Rhodora 84: 85100.

- 1986. Effect of fruit ingestion on Amelanchier seed germination. Bull. Torrey Bot. Club 113: 131134.

Rogers, J. S. 1942. The crane flies (Tipulidae) of the George Reserve, Michigan. Misc. Publ. Mus. Zool. Univ. Mich. 53: 1-128.

SChemske, D. W., AND L. P. Pautler. 1984. The effects of pollen competition on fitness components in a neotropical herb. Oecologia 62: 31-36.

SNow, A. A. 1986. Pollination dynamics in Epilobium canum (Onagraceae): consequences for gametophytic selection. Amer. J. Bot. 73: 139-151.

StePHENSON, A. G. 1980. Fruit set, fruit reduction, and the fruiting strategy of Catalpa speciosa (Bignoniaceae). Ecology 61: 57-64.

- 1981. Flower and fruit abortion: proximate causes and ultimate functions. Annual Rev. Ecol. Syst. 12: 253-279.

- 1984. The regulation of maternal investment in an indeterminate flowering plant (Lotus corniculatus). Ecology 65: 113-121.

$\longrightarrow$, AND R. I. BERTIN. 1983. Male competition, female choice, and sexual selection in plants. In $\mathrm{L}$. Real [ed.], Pollination biology, 109-149. Academic Press, New York.

Stosser, R., AND S. F. ANVAri. 1983. Pollen tube growth and fruit set as influenced by senescence of stigma, style and ovules. Acta Hort. 139: 13-18.

SwIETLIK, D., AND M. FAust. 1984. Foliar nutrition of fruit crops. Hort. Rev. 6: 287-355.

Thompson, J. N., AND M. F. Willson. 1979. Evolution of temperate fruit/bird interactions: phenological strategies. Evolution 33: 973-982.

VARGA, A., AND J. BrunNSMA. 1976. Role of seeds and auxins in tomato fruit growth. Z. Pflanzenphysiol. 80: 95-104.

Voss, E. G. 1985. Michigan flora. Part II. University of Michigan Press, Ann Arbor, MI.

Wareing, P. F., AND I. D. J. Phillips. 1978. Control of growth and differentiation in plants. $2 \mathrm{~d}$ ed. Pergamon, New York.

Weinbaum, S. A., AND R. K. Simons. 1976. Relationship of seed number to fruit set in apple. Fruit Var. J. 30: 82-84.

WheElWright, N. T. 1985. Fruit size, gape width, and the diets of fruit-eating birds. Ecology 66: 808-818.

Wilbur, H. M. 1977. Propagule size, number and dispersion pattern in Ambystoma and Asclepias. Amer. Naturalist 111: 43-68.

Willson, M. F., AND D. W. SChemske. 1980. Pollinator limitation, fruit production, and floral display in pawpaw (Asimina triloba). Bull. Torrey Bot. Club 107: 401-408.

WyatT, R. 1981. Components of reproductive output in five tropical legumes. Bull. Torrey Bot. Club. 108: $67-75$. 